\title{
Orion Capsule Parachute Assembly System (CPAS) Overload Testing Approach and Results
}

\author{
Jared S. Daum ${ }^{1}$ \\ NASA Johnson Space Center, Houston, Texas, 77059 \\ Michael L. Petersen ${ }^{2}$ \\ NAVAIR, China Lake, California, 93555
}

\begin{abstract}
The qualification of the Orion Capsule Parachute Assembly System (CPAS) system includes exposure to loads and dynamic pressures above the required values as validation of the parachutes' structural integrity. As outlined in the certification plan, each of the four parachutes of the system are to be subjected to $110 \%$ of their respective maximum dynamic pressure requirements. The Main and Drogue parachutes have satisfied this overload condition in drop testing and due to cost and schedule constraints, the Forward Bay Cover Parachute (FBCP) and Pilot parachute were subjected to the overload condition in the ground testing described in this document. The test objectives and pass/fail criteria were established and require the parachutes to achieve and maintain a target riser load (associated with a minimum of $110 \%$ dynamic pressure overload) for a minimum of three seconds while sustaining no failures of any structural members (vent hoop, radials, suspension line) or any damage which propagates into catastrophic failure of the canopy. Considering the assumptions and limitations associated with the ground testing (primarily non-uniform flow field of the ground test system and variations in parachute manufacturing), a method of establishing the desired overload condition was determined by the technical community and covers the 2-sigma bounds of the drag area distribution derived from drop testing. On June 27, 2017 the testing was executed at the High Velocity Airflow System (HiVAS) facility located at the Weapon Survivability Laboratory (WSL) at the Naval Air Warfare Center, Weapons Division (NAWCWD) China Lake. Engineering Development Unit (EDU) parachutes were used as pathfinders to gain experience with achieving the test conditions. Additional runs were executed to measure the airflow at the same location as the canopy skirt, although this data is not required to satisfy the test objectives and parachute pass/fail criteria. The qualification parachutes were successfully exposed to the target conditions and sustained only minor damage.
\end{abstract}

\section{Background}

The Capsule Parachute Assembly System (CPAS) utilizes 11 parachutes to safely slow the Orion spacecraft to a safe vertical velocity for touchdown. The deployment sequence is illustrated in Fig. 1. Three Forward Bay Cover Parachutes (FBCP) are mortar-deployed, providing sufficient force to ensure that the Forward Bay Cover (FBC) translates away from the Crew Module (CM) through the wake, mitigating the risk of recontact. Two Drogue parachutes are then mortar-deployed to slow and stabilize the CM for Main parachute deployment. Following the

\footnotetext{
${ }^{1}$ Aerospace Engineer, Aeroscience and Flight Mechanics Division, NASA/JSC

${ }^{2}$ Aerospace Engineer, Egress, Deceleration, \& Parachute Systems, NAWCWD China Lake, AIAA Senior Member
}

Trade names and trademarks are used in this report for identification only. Their usage does not constitute an official endorsement, either expressed or implied, by the National Aeronautics and Space Administration 
Drogues, three Main parachutes are mortar-deployed by individual Pilot parachutes, decelerating the Orion CM to a speed safe for splashdown. Part of the qualification of these parachutes is subjecting them to loading conditions beyond what is required of them to confirm that margin does indeed exits to the requirements.

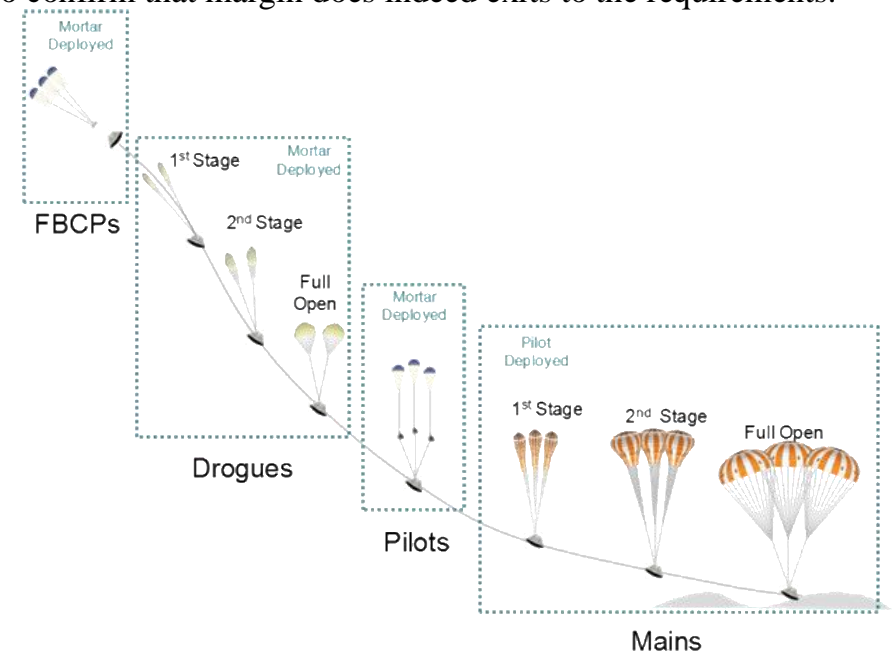

Fig. 1 Orion parachute deployment sequence.

\section{Overload Testing Validation Activity}

The intent of the overload testing validation activity (CPAS.SV.002) is to demonstrate that margin exists between the maximum expected parachute loading conditions and the capability of the parachutes.

\section{A. Certification Plan}

Per the certification plan for the Capsule Parachute Assembly System, CPAS shall:

Perform full-scale overload testing on each parachute type via airdrop or ground testing. The overload test will stress the assembled canopy at conditions above normal expectations to demonstrate margin of the structural grid.

The recommended target test condition for the CPAS overload tests is $110 \%$ of the applicable maximum deployment dynamic pressure as defined in the PDIC requirement for each canopy type. However, achievement of $110 \%$ dynamic pressure is not pass/fail criteria for the test. The test objectives will be documented in the applicable test plan based on the specific hardware and test method.

Observe system behavior and the structural integrity of the parachute. Inspect hardware for damage upon completion of the test.

The maximum dynamic pressure (q) is defined in the requirements specifications for CPAS and are seen in Table 1 .

\section{B. Drop Test History}

Table 1 summarizes the maximum dynamic pressure achieved during CPAS development and qualification testing relative to the dynamic pressure requirement for each parachute. 
Table 1 Maximum dynamic pressure deployments seen in CPAS drop testing.

\begin{tabular}{|rc|} 
Parachute & $\begin{array}{l}\text { Percent Over-q } \\
\text { on Drop Test }\end{array}$ \\
\hline FBCP & $-14 \%$ \\
\hline Drogue & $11 \%$ \\
\hline Pilot & $-14 \%$ \\
\hline Main & $10 \%$ \\
\hline
\end{tabular}

The Drogue and Main parachutes achieved the intended overload conditions in drop testing, but the FBCP and Pilot parachutes failed to achieve the $10 \%$ overload condition. Due to the cost and complexity of qualification drop testing, along with the relatively small size of the FBCP and Pilot parachutes, a ground test method was established which will satisfy the overload testing activity.

\section{Test Objectives and Pass/Fail Criteria}

The methods described in the following sections outline a test which meets the primary test objective:

1. Evaluate the performance of the FBCP and Pilot parachutes when subjected a minimum of $110 \%$ of their respective PTRS maximum dynamic pressure requirements:

a. FBCP Dynamic Pressure Requirement

i. The FBCP shall meet function and performance requirements when deployment is initiated within the deployment envelope

b. Pilot Dynamic Pressure Requirement

i. The Pilot parachute shall meet functional and performance requirements when deployment is initiated within the deployment envelope

In order for the test campaign to meet the test objectives, the follow criteria must be met:

1. The target load must be reached, instantaneously

a. It is known that variations in the flow field, noise in the measurements, and canopy dynamics will cause significant variations in the measured load, so the target load must only be reached instantaneously

2. The target load minus approximately $10 \%$ must be sustained at a minimum for three seconds

a. The intent is to differentiate between measurement noise (assumed to be around 10\%) and loss of drag capability in the parachute

In order for the parachutes to meet performance expectations during the overload conditions, the following pass/fail criteria must be met:

1. The target load minus approximately $10 \%$ must be sustained at a minimum for three seconds

a. The intent is to differentiate between measurement noise (assumed to be around 10\%) and loss of drag capability in the parachute

2. This will indicate that no damage was sustained that negatively affects the parachute performance for the expected duration of parachute operation

a. FBCPs function for a short time, after which the cover is jettisoned

b. Pilots begin to lift shortly after mortar fire, after which loading is significantly decreased

3. No failure of any structural members

a. Structural members include the vent hoop, radials, and suspension lines

4. Localized damage to any components of the canopy does not propagate into catastrophic failure

\section{Qualification Hardware}

The qualification test hardware includes the FBCP and the Pilot parachutes, modified to allow for ground testing yet retain all necessary performance properties of a flight parachute. The hardware was accepted as representative of flight by the CPAS project at a Hardware Acceptance Review (HAR), which documents the readiness and acceptance of the qualification hardware. In addition to this qualification hardware, Engineering Development Units (EDU) for 
each the FBCP and Pilot were utilized in the ground testing. These were modified in a similar manner to the qualification parachutes and were used to determine test conditions and throttle settings.

The FBCP is a Kevlar ${ }^{\circledR}$ conical ribbon parachute with 12 gores and a nominal diameter of 7 feet. Its suspension lines have a length of 14 feet and its riser has an unmodified length of approximately 77 feet. The unmodified overall distance from the canopy skirt to the riser attachment is approximately 90 feet when fully inflated. The riser length was shortened to approximately 7.4 feet to place the canopy in the proper region of the HiVAS flow field to achieve the desired dynamic pressure and to limit the flyout distance from the core of the flow during test as seen in Fig. 2

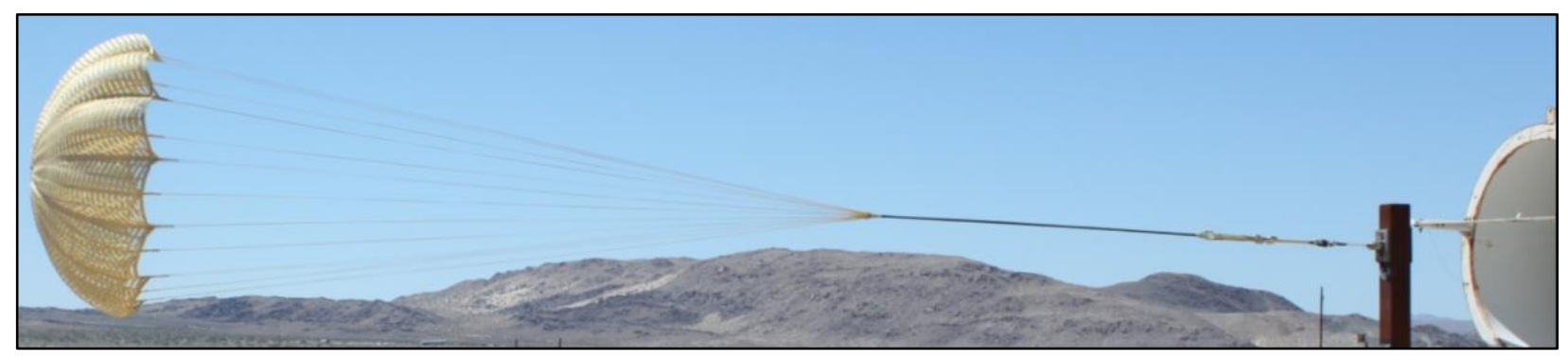

Fig. 2 Qualification FBCP in test configuration.

The Pilot is a conical ribbon parachute composed of Kevlar ${ }^{\circledR}$ and Nylon ${ }^{\circledR}$ with 12 gores and a 9.85 feet nominal diameter $\left(\mathrm{D}_{0}\right)$. Its suspension lines have a length of 11.3 feet and its riser has an unmodified length of approximately 57 feet. The unmodified overall distance from the canopy skirt to the riser attachment is approximately 67 feet when fully inflated. The riser length was shortened to approximately $10.4 \mathrm{ft}$ to place the canopy in the proper region of the HiVAS flow field to achieve the desired dynamic pressure and to limit the flyout distance from the core of the flow during test as seen in Fig. 3.

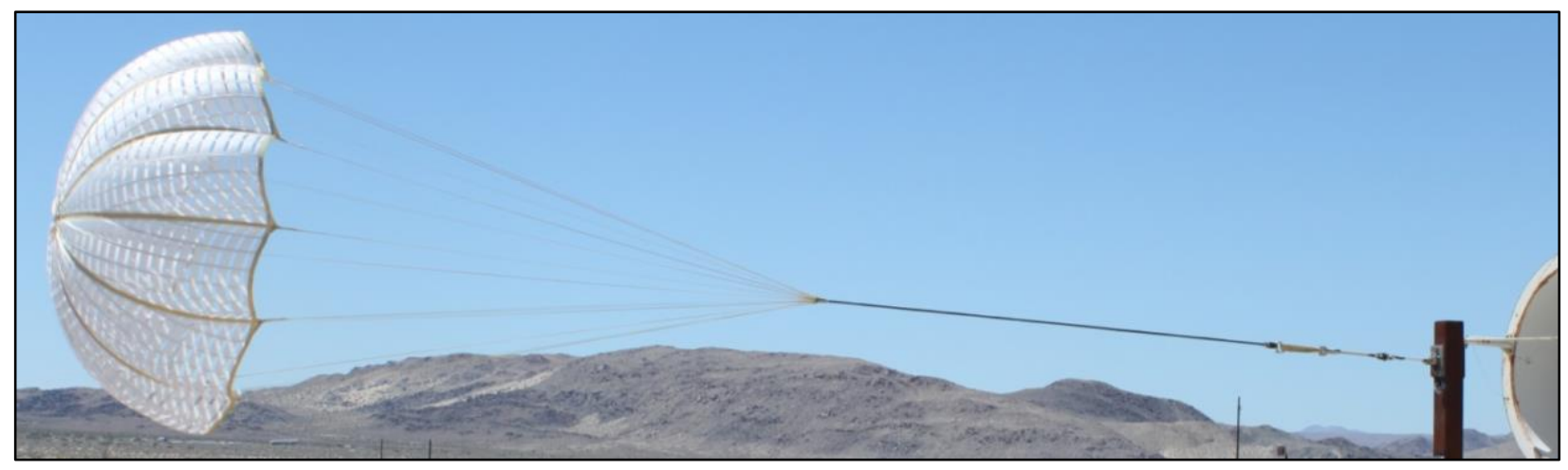

Fig. 3 Qualification Pilot in test configuration.

Since the EDU assets were already used in previous test campaigns, their condition is defined by previous damage reports, each with no significant damage to note.

\section{Test Method}

The following section describes the test method and test matrix. Due to ground testing limitations, significant assumptions were required regarding parachute performance to execute the test, which are also described.

\section{A. Test Method Overview}

The Egress, Deceleration, and Parachute Branch of the Naval Air Warfare Center, Weapons Division (NAWCWD), located in China Lake, CA., provides ongoing engineering support for CPAS as an independent government entity. Previous testing of the FBCP and Pilot parachute was performed in 2012 at the High Velocity Airflow System (HiVAS) facility located at the Weapon Survivability Laboratory (WSL) at NAWCWD China Lake. HiVAS was again selected to conduct the overload testing of both the FBCP and Pilot parachutes. Testing was conducted in accordance with applicable WSL standard operating procedures. 
The HiVAS facility, seen in Fig. 4, has four jet engines, the bypass air of which is ducted through a nozzle to create a flow with an exit core velocity up to 500 knots. The test parachutes were placed in this flow field and the output of the jet engines was controlled to achieve the desired dynamic pressure conditions at the parachute. The parachutes were anchored to a sting placed in the test area as seen Fig. 5

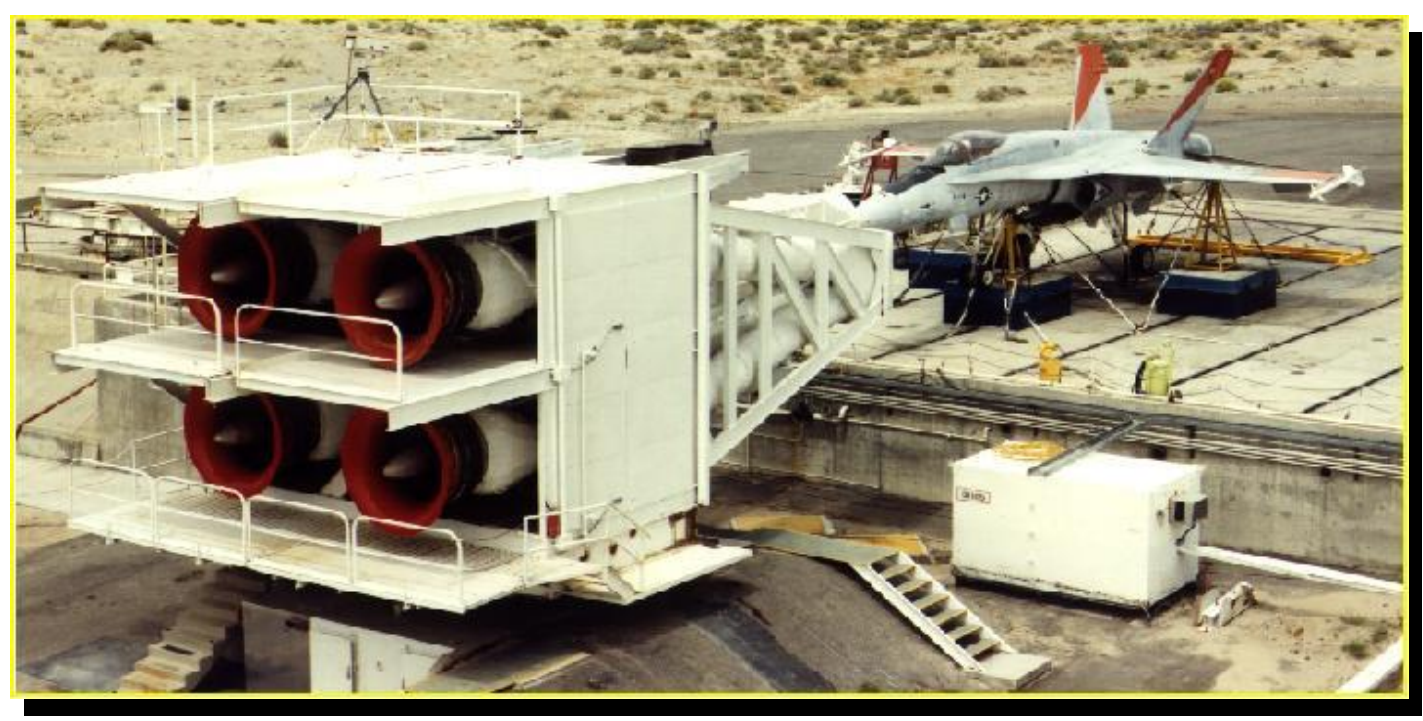

Fig. 4 HiVAS facility, stock photo.

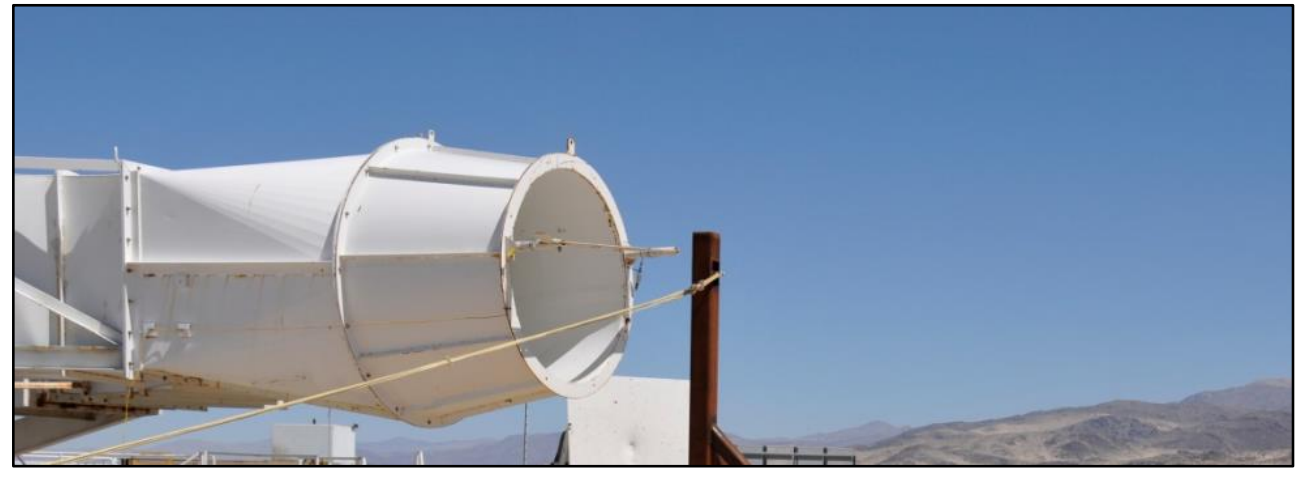

Fig. 5 HiVAS test area with parachute sting.

At the beginning of each test, the parachute started in a "non-deployed" condition outside of the HiVAS flow field and with the system at idle as seen in Fig. 6. The parachute was then manually inserted into the airflow at which point the engines were throttled up and the test began. Throttle adjustments were made using real-time riser load measurements to achieve the desired riser load.

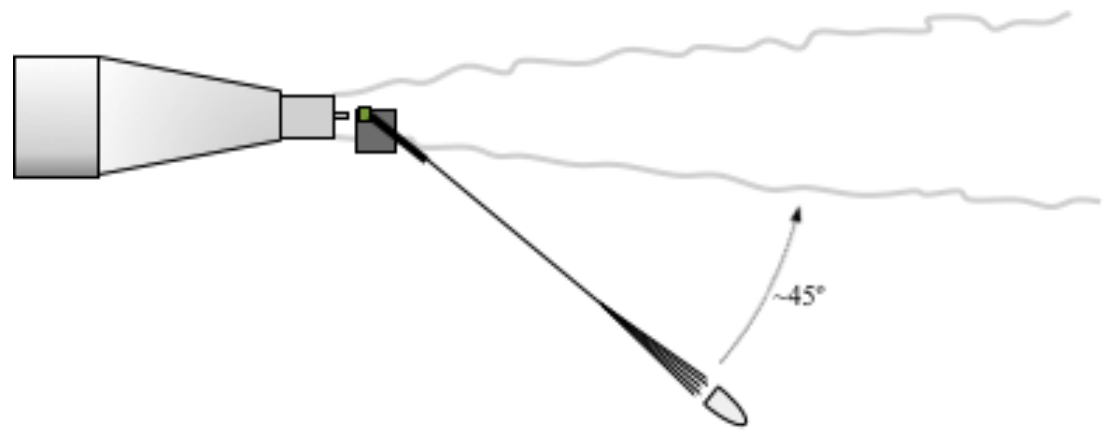

Fig. 6 Test setup in non-deployed condition, top view. 


\section{B. Assumptions and Limitations}

Drop testing with full instrumentation and flight reconstruction is the preferred method for overload testing of the parachutes. Due to cost and schedule constraints, the CPAS project decided to pursue ground testing for the FBCP and Pilot. With this programmatic decision comes testing limitations and assumptions required to execute the test and analysis as discussed in the Test Configuration Review/Test Readiness Review before testing. Ground testing with the HiVAS system imposes the following limitations:

1. The airflow generated by the HiVAS is nonuniform

a. Fig. 7 shows a representative profile of the HiVAS flow field using data collected from previous testing which included an FBCP and a Drogue parachute from another program

i. It can be seen that the flow velocity decreases substantially as a function of distance from the centerline of the flow

b. This means the effective canopy dynamic pressure cannot be directly measured

2. Direct measurement of riser load is an imprecise technique to establish the overload condition due to unknown canopy drag area

The assumptions made in order to execute this test and analyze the data are:

1. The drag area of the test articles is from the same population/distribution as described in the CPAS drop test-derived distributions

2. The non-uniform flow field of HiVAS does not have a significant impact on canopy performance as related to the results of the overload test

3. Test conductors can control the HiVAS throttle and react to parachute load in real time sufficiently enough to meet test objectives

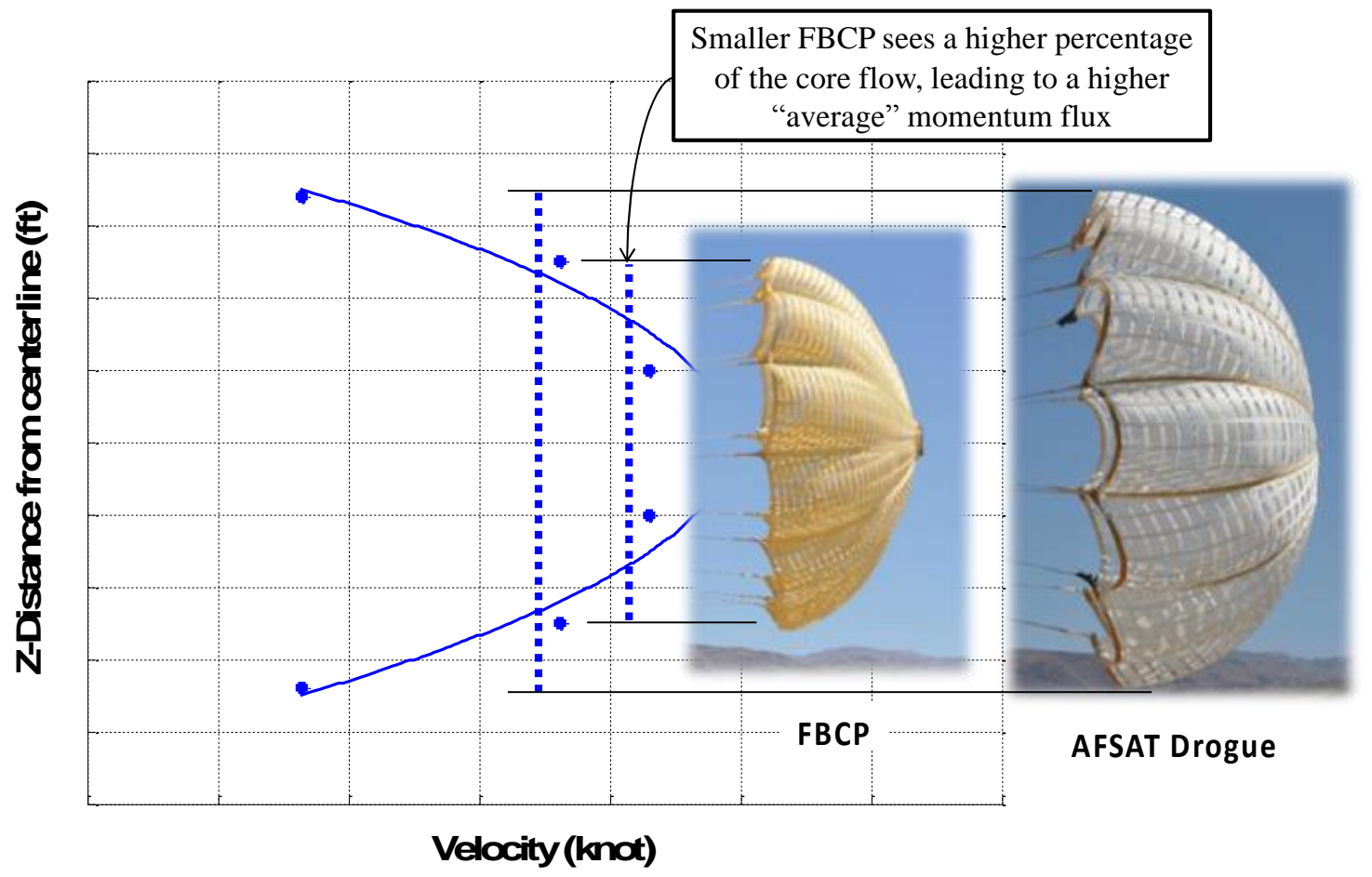

Fig. 7 Non-uniform flow field of HiVAS with representative inflated parachutes for visualization.

\section{Determination of Test Conditions}

In order to subject the parachutes to the appropriate overload dynamic pressure, given the assumptions and limitations described above, a technique was established to determine the test conditions. Given that the drag area of the parachutes is described by the distributions from CPAS drop testing, seen in Fig. 8 and Fig. 9 with various color data points indicating various drop tests, a given dynamic pressure can result in a range of parachute riser loads. 
Likewise, a given riser load can be achieved with various combinations of dynamic pressure and parachute drag area, seen in Eq. 1.

$$
\text { Load }=\text { Dynamic Pressure } * \text { Drag Area }
$$

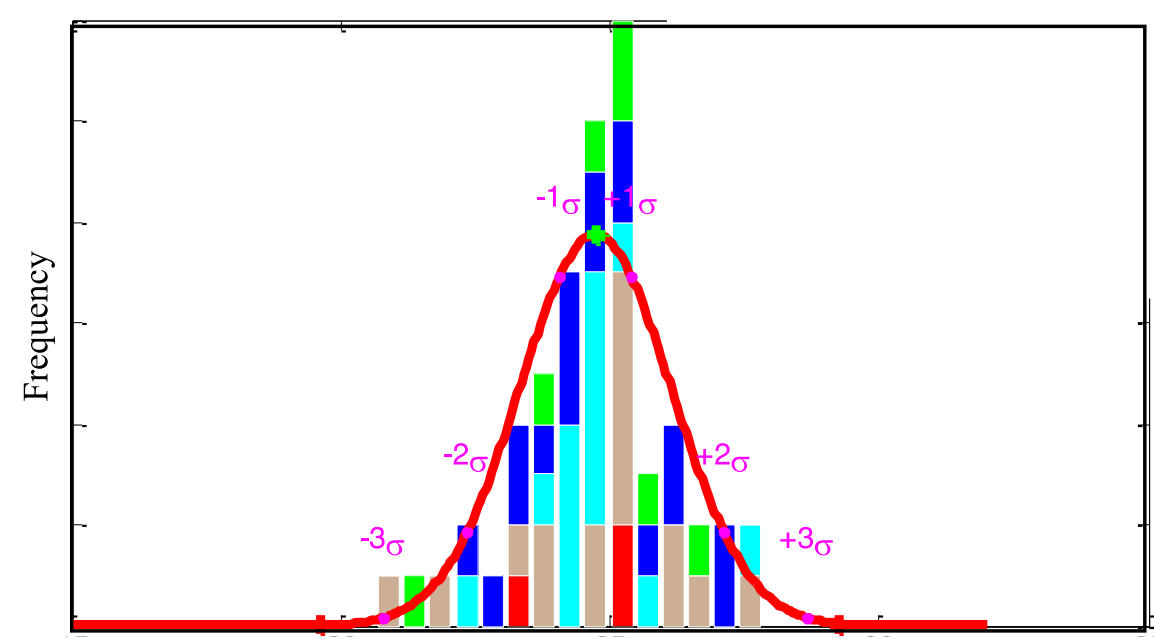

FBCP Drag Area

Fig. 8 CPAS test-derived FBCP drag area distribution.

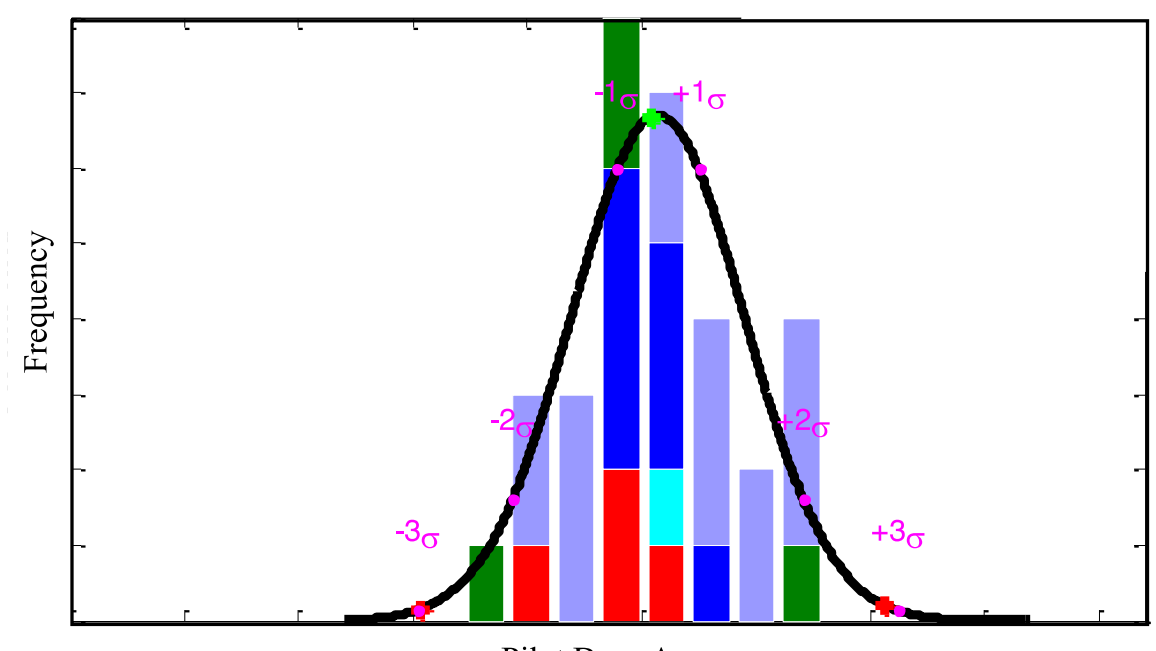

Pilot Drag Area

Fig. 9 CPAS test-derived Pilot drag area distribution.

Three conditions (two bounding and one centered) can be described:

1. Nominal

a. The parachute is assumed to have a nominal (or centered) drag area

b. Given the distribution of parachute drag area, there is a 50\% chance of undertest and a $50 \%$ chance of over-test

2. Max

a. The parachute is assumed to have a maximum drag area (to some sigma level)

b. This guarantees an under-test, with no (or little) chance of an over-test 


\section{Min}

a. The parachute is assumed to have a minimum drag area (to some sigma level)

b. This guarantees an over-test, with no (or little) chance of an under-test

The resulting range of possible dynamic pressures for each of these three scenarios for a target riser load, assuming a 3-sigma parachute, is seen in Table 2. A large range of over-test and under-test conditions can be seen. This shows that to guarantee the minimum $110 \%$ target at the 3-sigma level ("min" condition), a significant over-test is possible.

Table 2 Range of dynamic pressure levels, 3-sigma canopy.

\begin{tabular}{rrrc} 
& Condition & Upper Bound & Lower Bound \\
\cline { 2 - 3 } & Nominal & $129 \%$ & $91 \%$ \\
\hline \multirow{2}{*}{} & Max & $110 \%$ & $78 \%$ \\
& Min & $155 \%$ & $110 \%$ \\
\hline Nominal & $137 \%$ & $83 \%$ \\
\hline \multirow{2}{*}{} & Max & $110 \%$ & $66 \%$ \\
\hline & Min & $183 \%$ & $110 \%$
\end{tabular}

The technical team desired to achieve the target overload condition without exposing the parachutes to an excessive over-test, and thus it was decided to account for a 2-sigma parachute instead of a 3-sigma parachute (95.4\% coverage vs. 99.7\% coverage). The resulting bounds are seen in Table 3. Using the "min" approach allows sufficient confidence that the overload condition was achieved without subjecting the parachutes to excessive over-test conditions. The dynamic pressure conditions of a nominal drag area the FBCP and Pilot (most likely scenario) are 124\% and 132\%, respectively.

Table 3 Range of dynamic pressure levels, 2-sigma canopy.

\begin{tabular}{|c|c|c|c|}
\hline \multirow{4}{*}{ Uి } & Condition & Upper Bound & Lower Bound \\
\hline & Nominal & $123 \%$ & $97 \%$ \\
\hline & Max & $110 \%$ & $87 \%$ \\
\hline & Min & $138 \%$ & $110 \%$ \\
\hline \multirow{3}{*}{$\frac{\vec{\theta}}{\vec{\theta}}$} & Nominal & $128 \%$ & $92 \%$ \\
\hline & Max & $110 \%$ & $79 \%$ \\
\hline & Min & $154 \%$ & $110 \%$ \\
\hline
\end{tabular}

Once it is decided to protect for a 2-sigma parachute in the minimum condition, Eq. 1 can be used to determine the riser load to target during test. Using the inputs from the parachute drag area distributions, the target riser loads are calculated in Table 4.

Table 4 Target riser load calculations and inputs.

\begin{tabular}{|rcc} 
Parachute & $\begin{array}{c}\text { Overload } \\
\text { Condition }\end{array}$ & $\begin{array}{c}\text { Target Riser } \\
\text { Load (lb) }\end{array}$ \\
\hline FBCP & $110 \%$ & Calculated \\
\hline Pilot & $110 \%$ & Calculated \\
\hline
\end{tabular}

\section{Test Matrix}

The test matrix is outlined in Table 5. The run order and test matrix are outlined below and results in minimized setup time. Airflow data at both throttle set-points, without canopies, is collected to aid in analysis if needed. Since the riser load target is the test condition that defines the test and is directly measured and available to the operators, 
the airflow data is not required for analysis. Throttle targets will be generated using the pathfinder parachutes, but it is understood that due to variability in parachute construction, these will only be starting points for the qualification parachutes and real-time adjustments will be made.

Table 5 Test matrix.

\begin{tabular}{rcccccc} 
Test & $\begin{array}{c}\text { Pitot } \\
\text { Rake }\end{array}$ & $\begin{array}{c}\text { Pitot at } \\
\text { Nozzle }\end{array}$ & $\begin{array}{c}\text { Profile } \\
\text { Camera }\end{array}$ & $\begin{array}{c}\text { Boresight } \\
\text { Camera }\end{array}$ & Load Cell & $\begin{array}{c}\text { Target Load } \\
\text { (lbf) }\end{array}$ \\
\hline EDU FBCP & - & Yes & Yes & Yes & Yes & Calculated \\
EDU Pilot & - & Yes & Yes & Yes & Yes & Calculated \\
\hline Air Data Rake & Yes & Yes & - & - & - & - \\
Qual FBCP & - & Yes & Yes & Yes & Yes & Calculated \\
Qual Pilot & - & Yes & Yes & Yes & Yes & Calculated \\
Air Data Rake & Yes & Yes & - & - & - & -
\end{tabular}

VI. Instrumentation and Test Support Equipment

The primary measurement required to achieve the overload test objectives given the test limitations and assumptions is the parachute riser load. The hardware used to achieve the riser load measurement and sting attachment is listed in Table 6 and seen in Fig. 10 and Fig. 11. This (along with all other instrumentation and test support equipment) was provided by NAWC China Lake Crew Systems.

Table 6 Riser load measurement and sting attachment hardware.

ITEM

15k lb. load cell, Mouser MS3116E 8-4P 4-pin connector with $350 \mathrm{~W}$ Wheatstone bridge

\section{QUANTITY}

1 each

2 each

Kevlar webbing PIA-W-87130 Type VI Class 10, 1-inch width

Swivel GL 1721B-1, PPC 15.127

Custom 2-inch to 1-inch adapter, Kevlar webbing PIA-W-87130 Type XI Class 19, 2-inch width

1 each

Link Assembly 1" MS24553-1 (PS24553-1), 0.5inch diameter, $15 \mathrm{klb}$

2 each

Link Assembly 2" MS24553-1 (PS24553-1), 0.5inch diameter, $15 \mathrm{klb}$.

1 each 


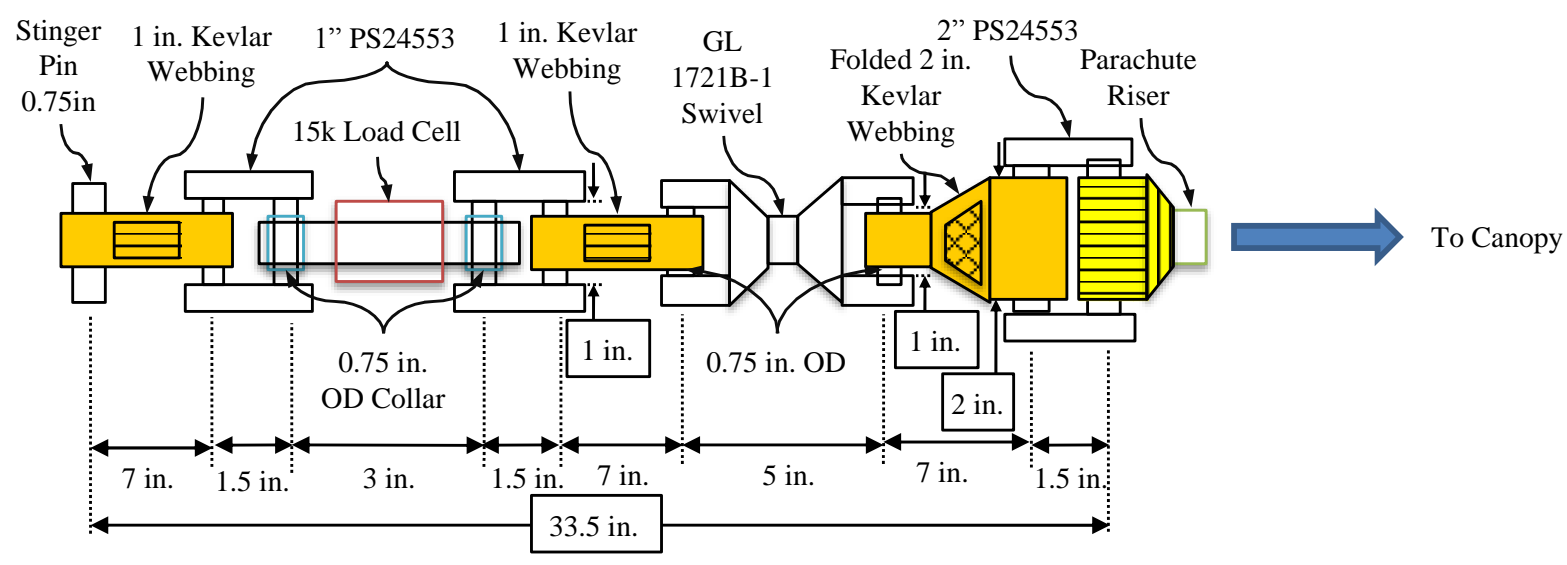

Fig. 10 Riser load measurement and sting attachment diagram.

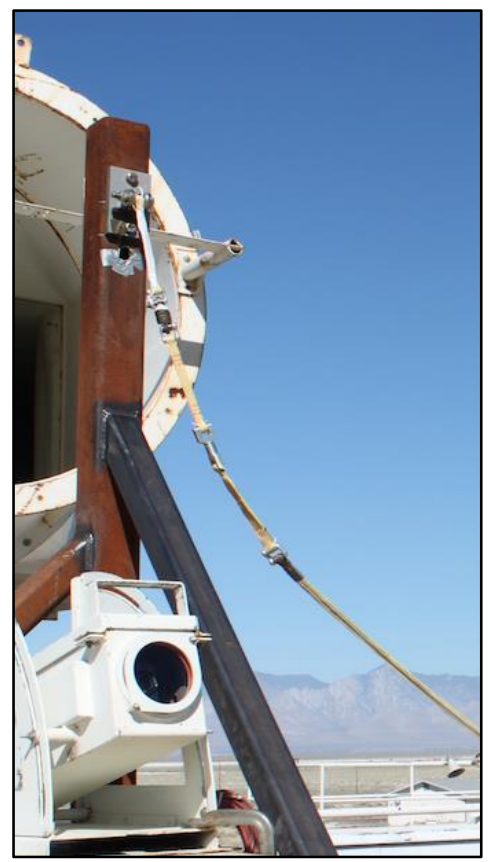

Fig. 11 Riser load measurement and sting attachment photo, with boresight camera.

Additional data collection included video and still photography, airflow rate, and manual recording of atmospheric conditions (found in the as-run procedure). Two primary camera views were planned: bore-sighted view looking at the canopy apex and a side view of the canopy approximately located at the center point of the inflated canopy as seen in Fig. 12. Still photos are used throughout the procedure to document the test setup, the parachutes during test, and all post-test inspections. Airflow rate is measured at the HiVAS nozzle for all tests and measured at the expected skirt location with pitot tube rake for the air data, or calibration, runs only. Due to a recording setup error, 
minimal high-speed video was captured for both boresight and side cameras and the views were captured at a lower frame rate.

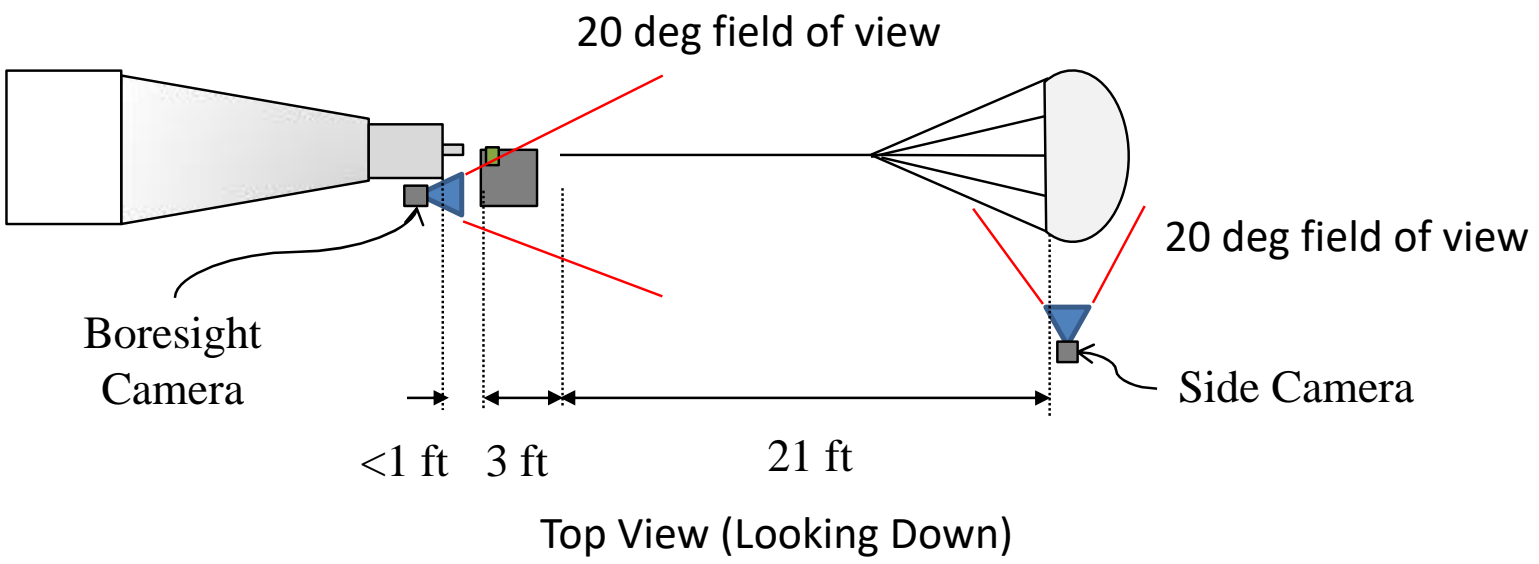

Fig. 12 Video camera setup.

\section{Test Execution, Results, and Inspection}

All tests were successfully conducted on June 26, 2017. The as-run procedure recorded details all of the steps conducted along with atmospheric conditions and preliminary inspections. Fig. 13, Fig. 14, Fig. 15, Fig. 16 show the riser load data and images for the four tests conducted. Variations in the riser load were observed to be significantly larger than anticipated due to nonuniformities in the flow, measurement noise, and parachute dynamics. These large variations are seen to instantaneously violate the approximate $10 \%$ test success criteria when taken at face value. The technical community concludes that the intent of that success criteria (maintaining parachute performance) is met when observing the trend of the data. The variation in load measurements appears consistent and within family for each run and there is no significant decreasing trend in riser load that would indicate a change in performance of the canopy throughout the run. All runs are shown to meet the test success criteria of meeting the target riser load and sustaining that load for a minimum of 3 seconds. The first run (EDU FBCP) exceeded the riser load for approximately 29 seconds - a result of the operators tuning their process for increasing and decreasing the riser load. 


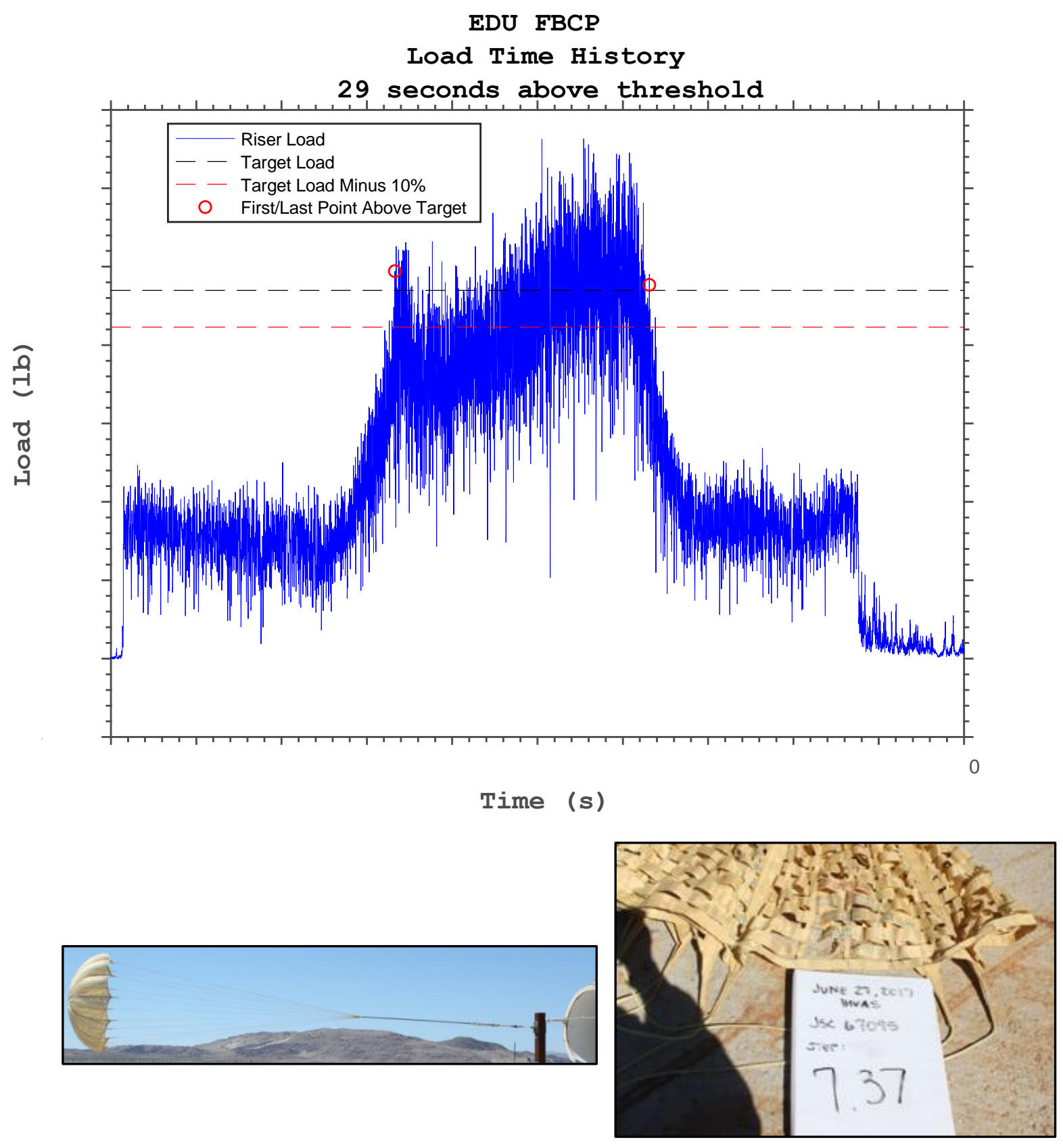

Fig. 13 EDU FBCP pathfinder run. 


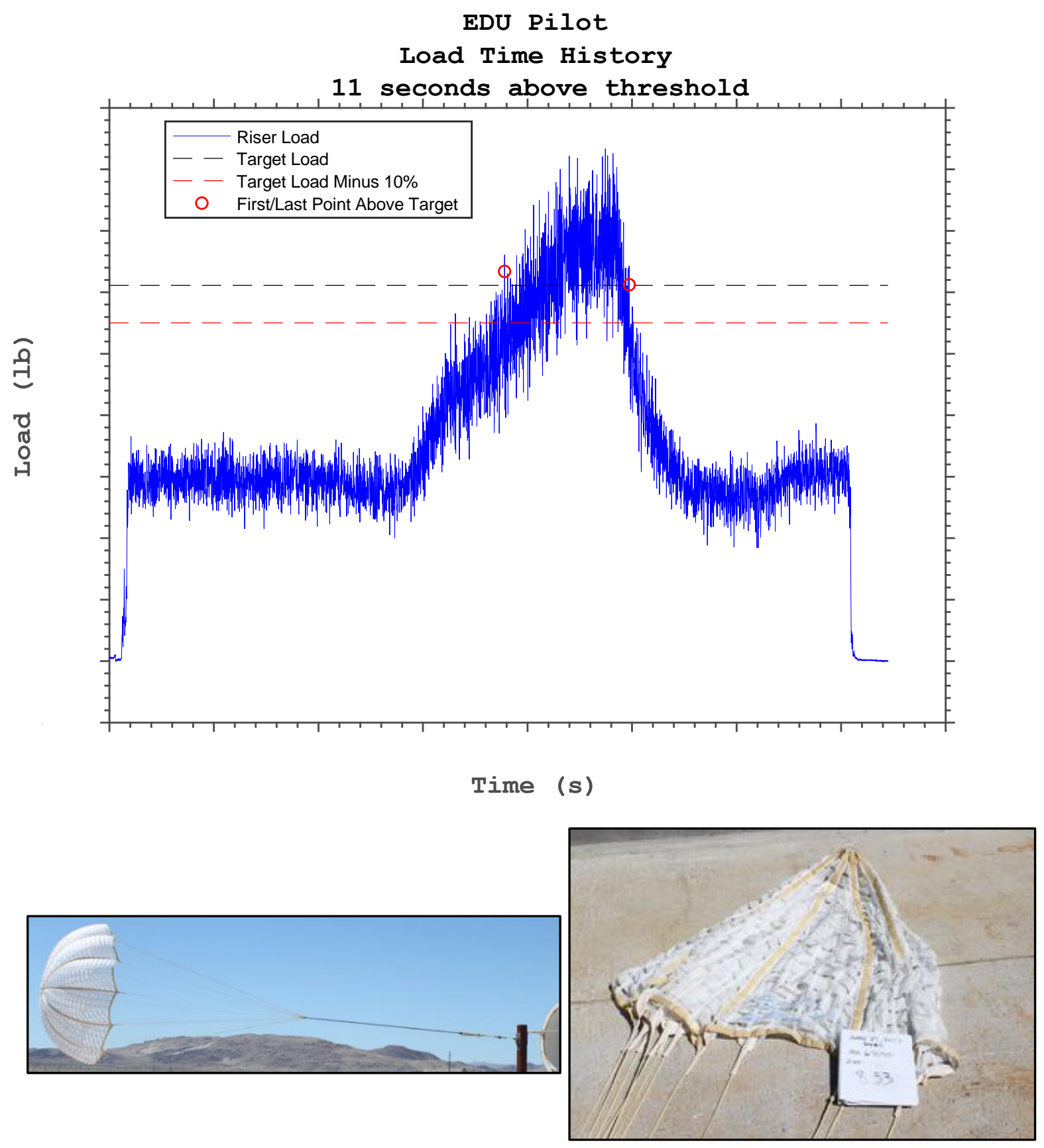

Fig. 14 EDU Pilot pathfinder run. 

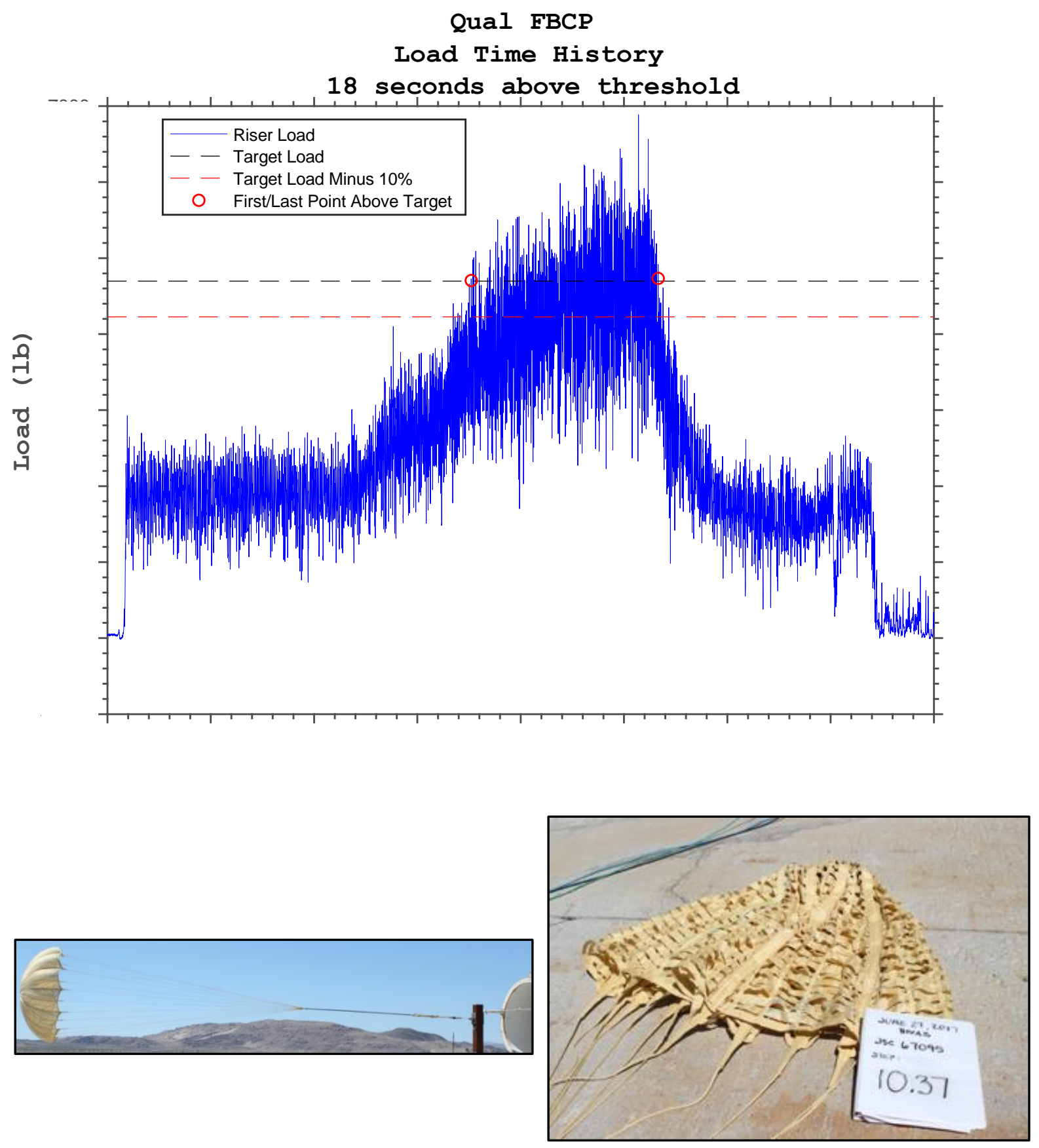

Fig. 15 Qualification FBCP run. 


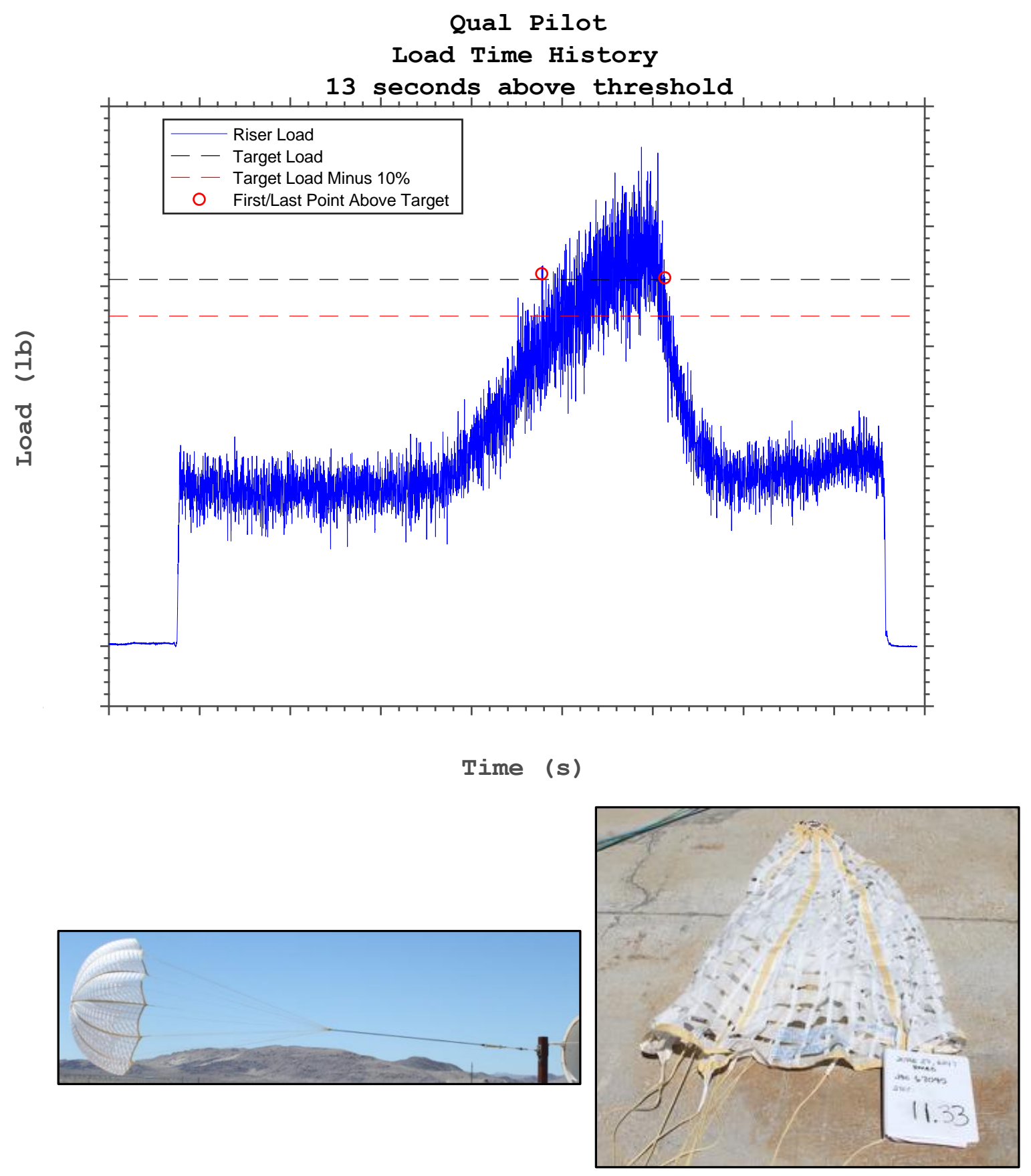

Fig. 16 Qualification Pilot run. 
Preliminary inspection of the parachutes at the test site revealed no damage which would significantly impact parachute performance, as described in the as-run procedure. The EDU FBCP sustained a broken/missing confluence and a torn ribbon at the skirt. The qualification FBCP showed minor combing on a ribbon. Detailed inspections were conducted at Airborne Systems North America. The EDU pathfinder parachutes were used in CPAS testing prior to this campaign and only cursory repairs were made before the overload testing. Prior damage that was left unrepaired was highlighted directly on the parachute before testing and included abrasion on suspension lines, tears on vent band, multiple areas of combing along horizontals. The qualification parachutes were first use and damages noted during the detailed post-test inspection, along with location, possible cause, and possible repair (if repairs were desired) are seen in Table 7 and Table 8. The report shows that the parachutes did not sustain any failure of any structural members and that any localized damage did not propagate.

Table 7 Qualification FBCP damage report

\begin{tabular}{cccc} 
Damage Location & Type of Damage & Possible Cause & Possible Repair \\
\hline Radial 3 & Dirt/stain & Ground & Clean \\
\hline Gore 7, horizontals & Minor combing & Inflation/flight & None \\
\hline Gore 12, horizontals & Minor combing & Inflation/flight & None \\
\hline Lines at confluence & Minor abrasion & Inflation/flight & None \\
\hline Buffer at end of riser & Fraying/thread pull & Ground & None
\end{tabular}

Table 8 Qualification Pilot damage report.

\begin{tabular}{|cccc|}
\hline Damage Location & Type of Damage & Possible Cause & Possible Repair \\
\hline Gore 8, 9 horizontals & Dirt/stains & Ground & Clean \\
\hline Gore 18, horizontals & Dirt/stains & Ground & Clean \\
\hline Gore 12, horizontals & Dirt/stains & Ground & Clean \\
\hline Confluence lanyards & Dirt/stains & Ground & Clean \\
\hline
\end{tabular}




\section{Conclusion}

The CPAS overload test described in this document, executed on June 27, 2017, met all test objectives and passed all pass/fail criteria to satisfy the validation activity as described in the CPAS Certification Plan. The test conditions were determined using parachute drag area distribution data from CPAS drop testing and a method that ensured a minimum of $110 \%$ of the maximum dynamic pressure requirement for a parachute within 2-sigma bounds of the distribution. In test, the qualification parachutes exceeded a $110 \%$ overload for greater than 3 seconds. Detailed inspections were conducted on all parachutes that revealed no significant damage, validating the design of the parachutes with the stated overload condition. Fig. 17 shows the test team after successfully executing the test campaign.

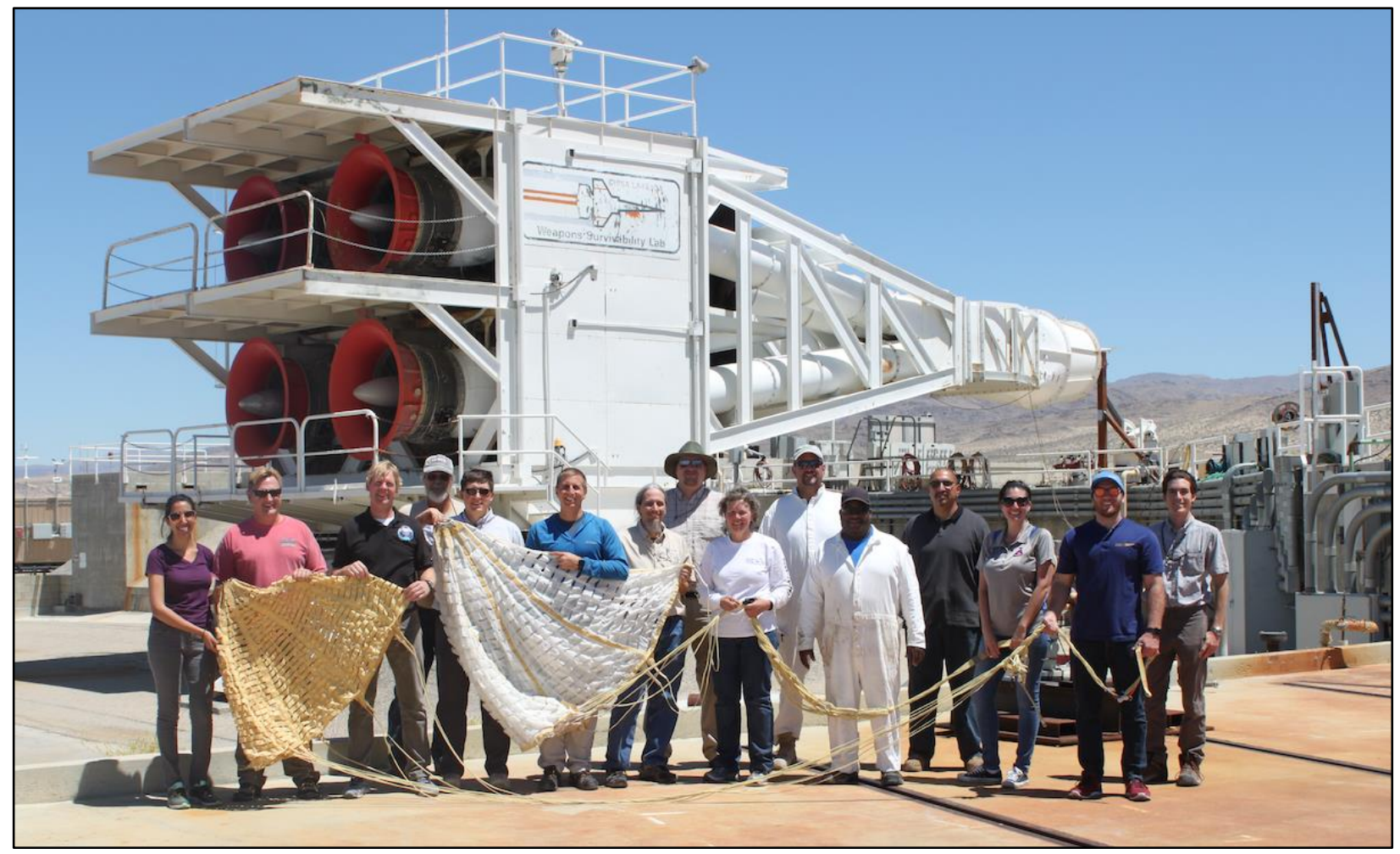

Fig. 17 Test team with qualification parachutes, post-test. 